\title{
A SENSE OF ENTANGLEMENT: ARTWORKS CONTRIBUTING TO CONNECTEDNESS
}

\author{
Lesley Brook
}

\section{INTRODUCTION}

In 2020, from 26 September to 2 October, the Dunedin School of Art was the venue for an exhibition called "The Complete Entanglement of Everything." Curators Bridie Lonie and Pam McKinlay selected artworks that addressed the causes, impacts and ways forward from the Anthropocene, an era in which the environment has been and is being changed by human behaviour.' What impact might such an exhibition have for its visitors?

Many social impacts are claimed for the arts and, increasingly, cultural organisations may be expected to demonstrate the value of what they do, in order to legitimise their existence and demonstrate accountability for their funding. ${ }^{2}$ Vermeulen and Maas suggest a five-step process for cultural organisations looking to measure their social impact and their progress towards achieving their intended goal or organisational mission. I suggest that the same steps can usefully be applied to measure the social impact of one exhibition.

The first step in Vermeulen and Maas's process is to set up a clear mission and determine impact goals. As curator, Bridie Lonie's hope was that experiencing the artworks would engage exhibition visitors emotionally with environmental issues through the artists' different understandings of and responses to the changing environment. She also hoped that the exhibition would help people to process their feeling and thinking about the effects of human behaviours on the environment by providing "space and time to negotiate what we feel." ${ }^{\prime \prime}$ And, last but not least, it was her hope that the exhibition would build a sense of community for visitors, through finding a perspective they shared and through exposure to other equally valid perspectives on environmental issues in the artworks. ${ }^{4}$

The second step suggested for social impact measurement is development of a Theory of Change. I began working with Bridie in 2019, developing a draft logic model in July of that year. The first iteration was not limited to the exhibition; it included the symposium, which was held contemporaneously, and a proposed community event which did not eventuate due to COVID-19, and also considered the potential for impacts beyond exhibition visitors. In our experience, steps I and 2 of Vermeulen and Maas's process occurred in tandem. The Theory of Change was refined and simplified over subsequent months in discussions as we considered what impact it would be reasonable to expect (and hence measure) shortly after the exhibition.

Vermeulen and Maas's third step is to monitor direct results. The exhibition was held, a map and printed catalogue were available at the exhibition, and subsequently a fuller catalogue ${ }^{5}$ and photographic record of the exhibition ${ }^{6}$ have been published online with open access. It is estimated by the curator that at least 250 people visited the exhibition during the week it was open, as well as symposium attendees, staff and students, at the Dunedin School of Art.

The fourth step is development of a plan to measure mission-related effects and the implementation of that plan. For my Master of Professional Practice degree, I undertook to evaluate the emotional impact of the exhibition for visitors. This article considers in particular the impact of the exhibition on viewers' feelings of connectedness - between their thoughts and feelings, with the environment, and with other people. The fifth step in impact measurement, using the results, will be considered in my conclusion below. 


\section{Theory of Change: The Complete Entanglement of Everything}

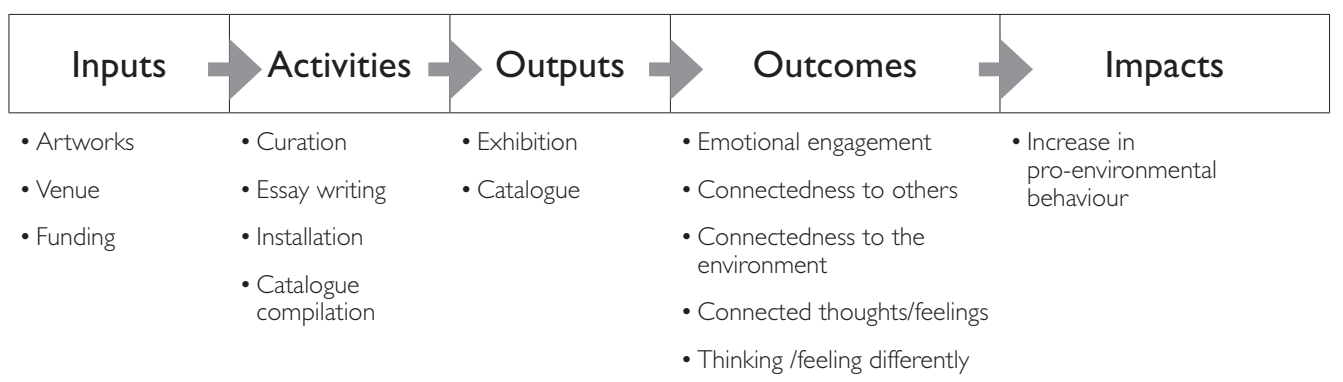

Figure I. Theory of Change developed for impact assessment of "The Complete Entanglement of Everything" exhibition, Dunedin School of Art, 26 September-2 October 2020.

\section{ART AND CONNECTEDNESS}

Emotional impact matters because emotion engages, ${ }^{7}$ motivating viewers to resolve for themselves the meaning of the artwork. ${ }^{8}$ As Minissale explains, generating that personalised interpretation of an artwork is itself a creative and emotionally rewarding experience. ${ }^{9}$ This personal experience can help people feel more connected in some way to the issue addressed in the artwork. ${ }^{10}$ Artworks therefore create opportunities for reflection and for disruption of previous patterns of thinking and feeling about an issue."

How does this process occur? Cues in an artwork generate connections in a viewer between their current experience of the work and a range of past experiences - memories, feelings and what they know already, ${ }^{12}$ for example about art, or about environmental issues. Minissale also acknowledges that context influences the interpretation of concepts contained in an artwork - so, for example, viewers who know that this is an exhibition of environmental art would factor that information into their consideration of the artworks. The arrangement of artworks by the curators in relation to each other and to the space they are shown in is also relevant..13

Minissale suggests that the experience of a contemporary artwork can be seen both as the viewer acting on the artwork, bringing the viewer's current and past experiences to bear upon it; ${ }^{14}$ and as the artwork acting on the viewer, to bring about a change in the viewer's system of knowledge and resulting actions. ${ }^{15}$ While it is not realistic to expect one exhibition alone to achieve a change in attitude, let alone lifestyle, the emotional and social experience of artworks can contribute to the cumulative effect on the viewer. ${ }^{16}$ Artworks can help to address some of the barriers which prevent people engaging constructively with an environmental issue such as climate change. ${ }^{17}$ These barriers include social norms, as well as the gap between knowing about climate change and feeling willing and able to do anything effective about it. ${ }^{18}$ For example, art can create empathy towards the natural environment by connecting people to nature and increasing their appreciation of its intrinsic value. ${ }^{19}$ Research by Merrick tells us that art can also acknowledge, and help people deal with, their emotions and feelings about the issues, and that by offering multiple perspectives art can help people to understand and appreciate others' points of view. ${ }^{20}$ 


\section{CASE STUDY - INTERVIEWS}

Twenty-five exhibition viewers participated in this case study. Most were recruited at the exhibition. I saw two at the exhibition and approached them afterwards, and one approached me after seeing the exhibition and hearing of the study. I met with each participant individually within two weeks of the exhibition closing - that is, within three weeks of each person viewing the exhibition.

After giving informed consent to participate in the study, each interviewee was shown 54 photographs of the installed artworks which I had taken, as visual prompts. While participants were diverse in age and in their experience of contemporary art, 24 had strong negative feelings about the effects of human activity on the environment.

During semi-structured interviews, participants were asked three questions related to the curator's hopes for the exhibition: Did one or more of the artworks give you a sense of connectedness with other people? Did one or more of the artworks give you a sense of connectedness with the environment? Did one or more of the artworks help you to connect what you know or have heard with how you feel?

\section{CONNECTEDNESS WITH OTHERS}

Twenty-three of the 25 participants identified at least one image that gave them a sense of connectedness with others. Together they selected 22 different artworks, giving seven different reasons for their selection/s.

Some participants also identified artworks which gave a sense of connectedness because the artist was personally known to them. That basis for connectedness is excluded from this analysis in order to focus on connectedness formed by the artwork, rather than for reasons attributable to a prior relationship.

\section{Universal experience}

Artworks which evoked a common or shared experience gave participants a sense of connectedness with others through feeling that "we are all in this together." This shared experience could be real - for example, using hand sanitiser or discussing an artwork with other viewers. The shared experience might also be imagined, such as the sense of being refugees from, or otherwise learning to live with, a damaged environment. "I felt like more than just me has experienced this."

\section{Personal experience}

Some artworks portrayed what was a highly relatable experience or perspective for participants, giving them a sense of connection either with those shown in the artwork or with the artist. These were real experiences by participants - picking up rubbish, knitting, hearing similar sounds and sharing the same way of seeing things as the artist. Prior personal experience of the artwork in either a public or social setting also gave a sense of connectedness with others.

\section{Shared feelings}

Some participants selected artworks because they felt connected with others through shared feelings. This could be either a sense that the participant's emotional state was shared by others, or gaining a sense of the pathos or dread that others feel. For other participants it was a feeling that we are not on our own, that we have a shared human condition, now and across time, that gives a sense of connectedness with others.

\section{Collaboration}

For some participants, collaboration gave a sense of connectedness with others. Some artworks which portrayed groups of people made participants think of people working together collaboratively and helping each other. Other artworks spoke to participants of collaboration in the making of the artwork - for example, the community associated with Māori carving. 


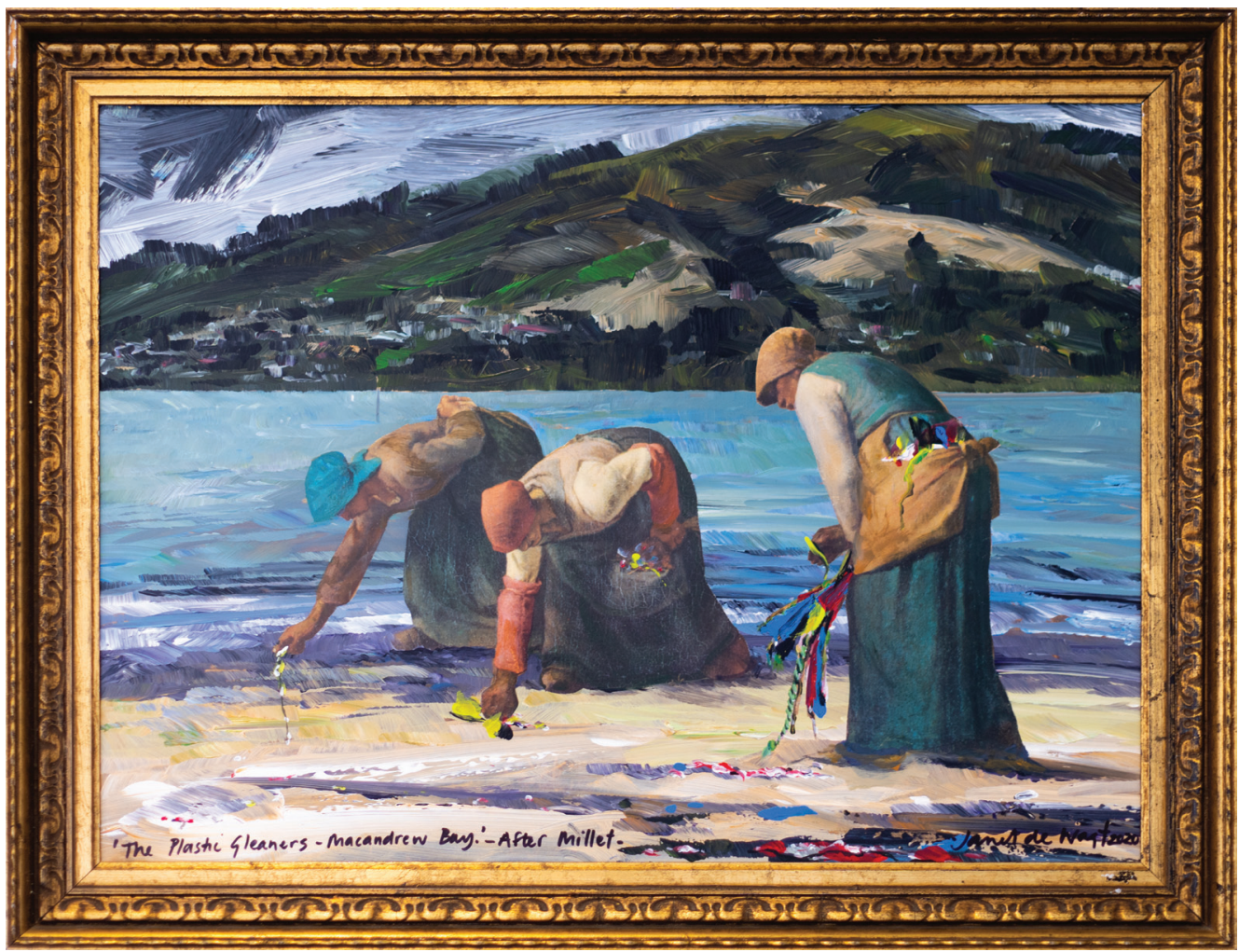

Figure 2. Janet de Wagt, The Plastic Gleaners - Macandrew Bay. After Millet ["artwork 45"], acrylic on board, $59 \times 53 \mathrm{~cm}$. Photograph: Jodie Gibson.

5. Message

Another source of the sense of connectedness with others was the message. Some participants felt connected with others because artworks such as posters had a message for people. Others felt connected through identification with the artist's message.

\section{Human figure(s)}

Seeing people or the human form portrayed in an artwork was enough in itself to give some participants a sense of connectedness with others.

\section{Identification with artist}

Some participants selected artworks because they felt connected with the artist in some way other than personally knowing them already. They identified with the artists through connection with and appreciation of their artwork. "I feel connected with the person who created the art, someone who thought to make these paintings that I feel connected with and so I feel connected with the person who created the art even though I don't know them personally." 


\section{CONNECTEDNESS WITHTHE ENVIRONMENT}

Twenty-three of the 25 participants identified at least one artwork that gave them a sense of connectedness with the environment. Together they selected 34 different artworks, giving seven different reasons for their selection/s.

I. Local place

Some participants selected artworks that portrayed a place that was familiar to them. These artworks were effective at engaging viewers who recognised the place, because they drew on an existing connection between the viewer and the place, whether that was home for them and/or a place they had enjoyed spending time in. For two participants, an artwork that drew attention to what was local also contributed to a sense of connectedness with the environment.

\section{Animals}

Two participants chose artworks portraying animals, showing them at risk, because they placed a high value on animals.

\section{Damage to the environment}

For some participants, the sense of connectedness with the environment arose out of the damage being done to the environment by humankind - for example, digital waste and animal extinctions.

\section{Materials}

The materials used by the artists contributed to a sense of connectedness with the environment for some participants, especially natural materials, but they also appreciated a sense of materiality.

\section{Immersion}

Some artworks evoked a very positive experience for participants, such as being immersed in nature. Participants used words like "mesmerising," "luscious," "all-encompassing" and "sensual." For another, "that sense of pausing and just really looking at nature was a good thing."

\section{Shared feelings}

Some participants selected artworks that evoked a perspective on the environment which they shared. This could be positive if the participants identified with how the artist had shown the environment. Other participants felt connected with the environment through being reminded of negative feelings they had about what was happening to it.

\section{Positive portrayal of the environment}

Finally, the portrayal of the beauty of natural environments in the artworks also gave participants a sense of connectedness to the environment. Most of these artworks included landscapes or vegetation and gave pleasure and delight.

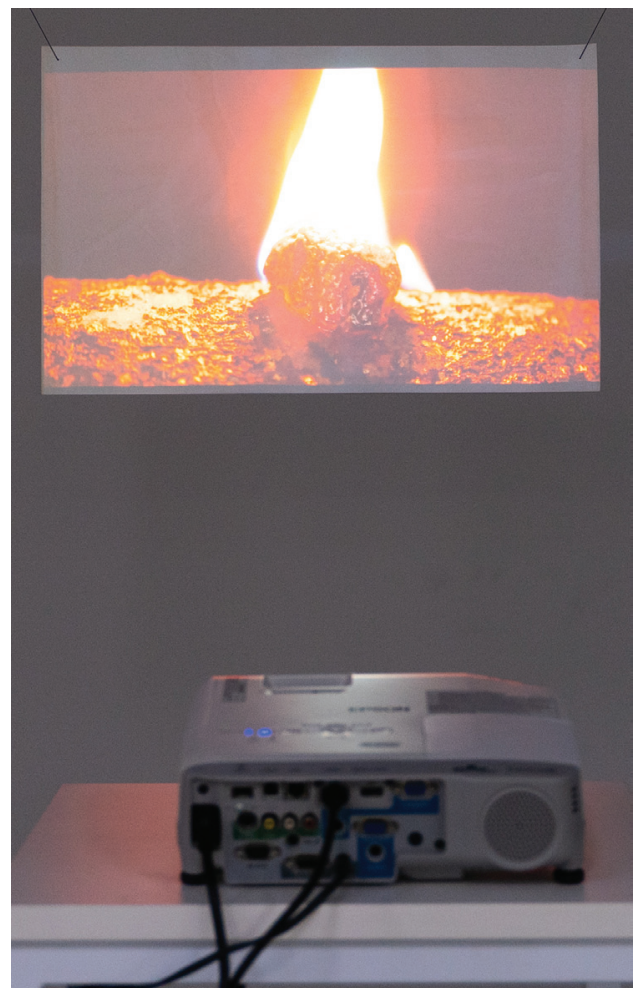

Figure 3. Janine Randerson, Kāpia: Fossils and Remedies

["artwork 9'], 2020, single-channel viso on Hahnemule paper screen immersed in fallen kauri leaves and bark solution, thread, sound. Photograph: Jodie Gibson. 


\section{CONNECTING THOUGHTSWITH FEELINGS}

All but one of the 25 participants had strong negative feelings about the effects of human activity on the environment. In answer to my question about connecting thoughts with feelings, two participants said none of these artworks helped them connect what they knew with how they felt. Three others also said no, explaining that the artworks did not give them new knowledge and that they already had a good sense of their own emotions about what they knew.

There were 20 participants who identified one or more artworks which helped connect thoughts and feelings for them. Three of these did not add to their comments earlier in the interview about the same artworks. One felt able to connect information about underwater sounds with how an artwork made them feel. For another participant, how they felt about an artwork connected with their knowledge of New Zealand's history.

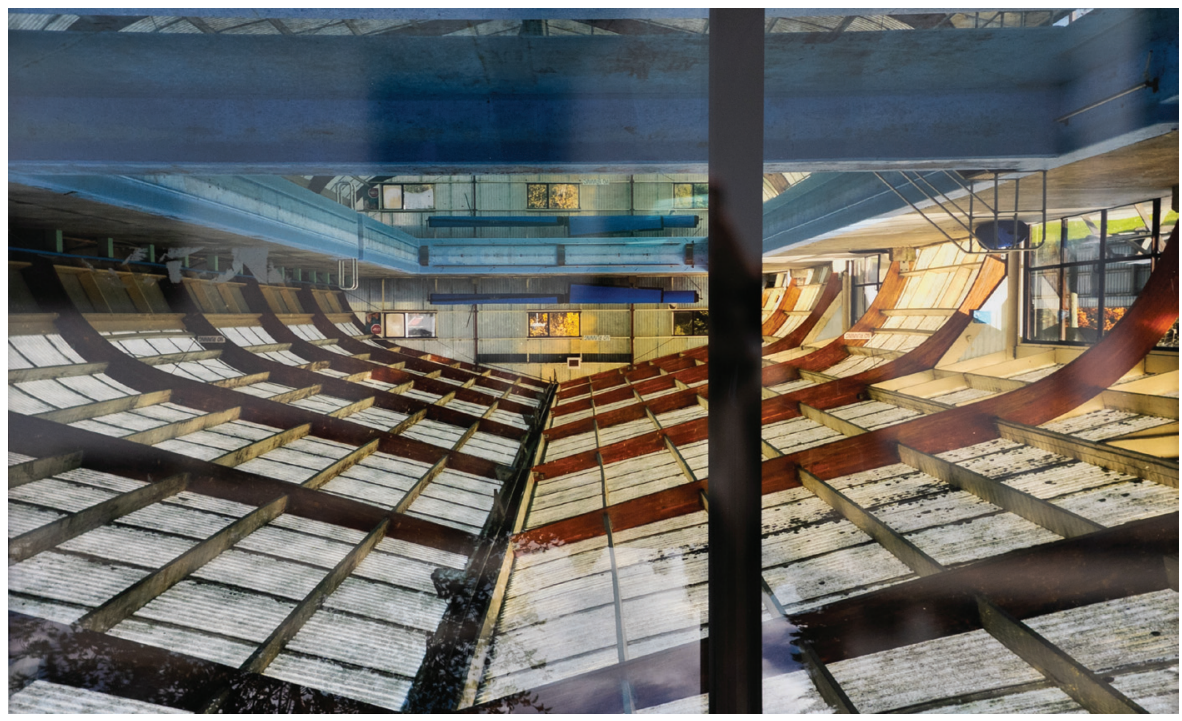

Figure 4. Mark Bolland, Loop ["artwork 40"], 2012 ,

inkjet print on archival Epson matte paper, $75 \times 50$ cm. Photograph: Jodie Gibson.

Two participants each identified an artwork which helped connect the negative things they knew about what was happening to the environment with feelings that were positive:

"For me it went from, like, "I understand why she's looked at all of these plastics and how they're all connected, and the computers,' but then it was also, like, 'Oh, it's very overwhelming and also kind of, like, sublime,' because the colours are so saturated. So that was quite an interesting connection between the two."

"I don't know if it is an ark, but it certainly felt like an ark, like a religious hope, [a] hope boat-building thing and, and so ... it triggered this connection between we are at a time of floods, of biblical floods, and people are preparing even if I'm not. So that I guess what I know and what I feel - there was something in that boat shape that just said 'Oh look the floods are coming and there are people out there preparing."”

The remaining 13 participants identified artworks that they said connected what they knew about the damage to the environment with their negative feelings about that. 


\section{CONNECTEDNESS WITH AND WITHIN ARTWORKS}

In the earlier part of the interview, before they were asked the three explicit questions about connectedness, participants described their strongest positive and strongest negative emotional responses to the artworks. Eight participants mentioned connection in some way when talking about their emotions.

Connection between artwork and observer was one way of describing engagement. One participant said, "I would walk past things if I didn't, like, have an initial connection." Similarly, two other participants said of two different artworks, "it connected immediately" and, "I'm probably personally connected to it."

Connections within the artwork mattered. For one participant, the way that the materials and purpose of an artefact connected together evoked a positive emotional response for two different artworks. Conversely, three participants attributed their negative emotional responses in part to a lack of connection:

- between an artwork and its related text;

- $\quad$ between "the materials and the way it's presented"; and

- between an artwork and its genre.

Two participants anticipated the later question about connectedness with other people. One participant referred to "relatability to how [the artist] views landscape," and another said, "I just really related to that because ... it makes you feel not alone in your experience."

Connectedness with the environment was also anticipated in the earlier discussions about emotional responses. For example, one participant referred to nostalgia for "my relationship to land." One artwork connected a participant with "the impact that climate change has" on animals. The same participant felt that another artist used humour to make "connections with place." Another participant described their positive emotional response in these words: "a sense of connectedness, and just a little bit of nostalgia and possibly local pride and that sense of 'ah, I know this, I know this."' Four participants described their familiarity with the places they could identify in four artworks - for three of them, that familiarity contributed to a positive emotional response, but for the fourth it was a negative influence because the two artworks showed negative things happening "right where I live."

While there were no explicit examples of people connecting thoughts with feelings in their explanations of their emotional responses, some participants did describe other kinds of connections that the artworks made for them and which contributed to positive emotional responses to artworks:

- "A lot of what I immediately connected to is marine and ocean tones, and it brought a lot of that connection up."

- "that made me feel connected ... from a perspective of ... the ancient through to now."

- " "the idea of ... a connectedness with the past and the idea that we're all fossils."

- A connection between the negative effects of human activity on the environment and a positive response to that in the participant's own practice.

Participants spontaneously referred to connection or relatability in describing their emotional responses to the artworks. This revealed additional types of connections which artworks made for participants, as well as those explicitly explored in the questions asked later in the interviews. 


\section{DISCUSSION}

This qualitative study set out to evaluate the connections which the artworks in the exhibition "The Complete Entanglement of Everything" made for 25 viewers. By the time I asked study participants three explicit questions about connectedness, eight of them had already recognised some connections which artworks had made for them.

The first explicit question about connectedness explored connection with others. Six of the 22 artworks selected by participants in answer to this question portrayed one or more people, and one was in the form of a human figure. The remaining 15 artworks did not portray people. While the portrayal of people in artworks can contribute to emotional responses to art, ${ }^{21}$ this study shows that portraying people or a human figure is not necessary for artworks to evoke feelings of connectedness with others. There are many other ways that art can connect a viewer with other people - such as shared feelings, shared personal or universal experiences, collaboration including participation in the making of the artwork, and identification with a message or with the artist.

The second question asked about connectedness with the environment. Artworks showing beauty, using natural materials, or evoking a positive immersive experience of nature gave participants a sense of connection with the environment. So did artworks that showed what people cared about, such as animals and waste; Minissale notes that empathy assists with the process of making sense of an artwork. ${ }^{22}$ Artworks which depict a local environment are more meaningful to viewers, according to Merrick, ${ }^{23}$ and that was borne out in this study, too.

Thirdly, I asked participants about whether any of the artworks helped them connect their thoughts and feelings. Eighty percent of participants were able to identify artworks which had this impact for them. Two participants in particular, who connected negative thoughts about the environment with positive feelings, illustrated Minissale's assertion that in the process of viewing and making sense of what is viewed, viewers of artworks connect thoughts and feelings that are otherwise quite disparate..$^{24}$ For 13 other participants, connecting negative thoughts and feelings seemed to at least affirm their perspective, adding another layer to their accumulated experiences.

This study demonstrates that viewing artworks generates connections not only between viewers and the works, but also within the viewer, between the viewer and the artist or others, and between the viewer and the environment.

\section{CONCLUSION}

The fifth and final step in Vermeulen and Maas's process for measurement of social impact by cultural organisations is to expand the impact measurement and use the results for strategic purposes. ${ }^{25}$ By asking 25 exhibition visitors about the emotional impact of the exhibition for them, this research explored what the exhibition achieved. The connections made by artworks in this exhibition for viewers participating in the study included increased connectedness between thoughts and feelings, with other people, and with the environment. Thus, the interviews with participants indicate that the exhibition fulfilled the curators' vision and goals.

Measurement of social impact not only asks about what has been achieved for reporting purposes; it can also seek to improve understanding of "what works in order to contribute to social issues, what is most effective in solving these social issues, how these processes work" (emphasis in the original) and what can be learned. ${ }^{26}$ It is hoped that these findings will be of interest to artists and curators by shedding more light on the various ways in which artworks make connections within and for viewers. 
Lesley Brook (ORCID ID: https://orcid.org/0000-000 I-6678-5 I79) is the research projects coordinator in the Research and Postgraduate Directorate at Otago Polytechnic. Her research interest is in ways of achieving and evidencing the impact of research, especially of art research.

I Bridie Lonie, introduction to Dunedin School of Art, The Complete Entanglement of Everything (Dunedin: Otago Polytechnic, 2020). Bridie Lonie and Pam McKinlay were joined by Marion Wassenaar for the final curation.Bridie Lonie, "Complexity and Entanglement In Exhibiting Climate Change", Scope (Art\&Design) 22, 2021, 38

2 Marjelle Vermeulen and Karen Maas, "Building Legitimacy and Learning Lessons: A Framework for Cultural Organizations to Manage and Measure the Social Impact of Their Activities," The Journal of Arts Management, Law, and Society, $51: 2$ (2021), I-16, https://doi.org/10.1080/10632921.2020.1851839.

3 Bridie Lonie, introduction to The Complete Entanglement of Everything, https://issuu.com/dunedinschoolofart/docs/the_ complete_entanglement_of_everything_exhibition.

4 Bridie Lonie, personal communication, 10 March 2020.

5 Dunedin School of Art, The Complete Entanglement of Everything (Dunedin: Otago Polytechnic, 2020).

6 Dunedin School of Art, The Complete Entanglement of Everything, 28 SEP-2 OCT, 2020, https://www.flickr.com/photos/ dunedin_school_of_art/albums/72 I 577 | 6560772858?fbclid=IwAROMARuSwED_7ynfllxHaV-jil9q9uOU8JToZAeH9tF5T I G JqRweZc4su2o. "Photo documentation of the exhibition by Jodie Gibson."

7 Liselotte J Roosen, Christian A Klöckner and Janet K Swim, "Visual Art as a Way to Communicate Climate Change: A Psychological Perspective on Climate Change-related Art," World Art, 8:I (20 I8), 85- I I0, https://doi.org/l0.1080/2I 50089 4.2017.1375002.

8 Gregory Minissale, The Psychology of Contemporary Art (New York: Cambridge University Press, 20I3), $26,225$.

$9 \quad$ Ibid., I73-4, 312.

10 Roosen, Klöckner and Swim, "Visual Art."

II Ibid; Minissale, Psychology of Contemporary Art, 145, 228.

12 Shiralee Hudson Hill, "A Terrible Beauty: Art and Learning in the Anthropocene," Journal of Museum Education, 45:I (2020), 74-90, https://doi.org/ I 0. I 080/I 0598650.2020. I 723357; Minissale, Psychology of Contemporary Art, Xv.

13 Minissale, Psychology of Contemporary Art, 10, 273.

14 Ibid., 266.

15 Ibid., 337.

16 Malcolm Miles, "Representing Nature: Art and Climate Change," Cultural Geographies, 17:1 (2010), 19-35, https://doi. org/ 10.1 I 77/ 1474474009349997 ; David J Curtis, Nick Reid and lan Reeve, "Towards Ecological Sustainability: Observations on the Role of the Arts," Sapiens, 7:I (2014), http://journals.openedition.org/sapiens/I 655.

17 Kath Merrick, The Power of Art to Engage the Public on the Impacts of Climate Change on the Coast (Western Australia: Curtin University, 201 I). http://citeseerx.ist.psu.edu/viewdoc/summary?doi= I 0. I. I.452.3275

I8 Irene Lorenzoni, Sophie Nicholson-Cole and Lorraine Whitmarsh, "Barriers Perceived to Engaging with Climate Change among the UK Public and Their Policy Implications," Global Environmental Change, 17:3-4 (2007), 445-59, https://doi. org/10.1016/j.gloenvcha.2007.01.004.

19 Curtis, Reid and Reeve, "Towards Ecological Sustainability"; Merrick, The Power of Art; Anna Keller et al., "Contextualizing Information Enhances the Experience of Environmental Art," Psychology of Aesthetics, Creativity, and the Arts, I4:3 (2020), 26475, https://doi.org/10.1037/aca0000213.

20 Merrick, The Power of Art.

21 Minissale, Psychology of Contemporary Art, 84.

22 Ibid., 86-7, 229.

23 Merrick, The Power of Art, 47.

24 Minissale, Psychology of Contemporary Art, 46, 61, 262, 266.

25 Vermeulen and Maas, 'Building Legitimacy."

26 Ibid., 4. 